\title{
ISOMORPHIC DEGREE SPLITTING GRAPHS
}

\section{SELVAM AVADAYAPPAN*, M. BHUVANESHWARI}

\author{
Research Department of Mathematics, \\ VHNSN College, Virudhunagar - 626001, India \\ *Corresponding author: selvam_avadayappan@yahoo.co.in
}

ABSTRACT. Let $G(V, E)$ be a graph and let $V_{i}$ denote the set of all vertices of degree $i$. The degree splitting graph $D S(G)$ of $G$ is obtained from $G$, by adding a new vertex $w_{i}$ for each partition $V_{i}$ such that $\left|V_{i}\right| \geq 2$ and joining $w_{i}$ to each vertex of $V_{i}$. In this paper, we characterise graphs for which degree splitting graphs are trees or unicyclic. We develop an algorithm to check whether the given graph is a degree splitting graph of a graph. Also we establish some necessary conditions for the existence of non isomorphic graphs to have isomorphic degree splitting graph.

2010 Mathematics Subject Classification. 05C78.

Key words and phrases. Splitting graph, co - splitting graph, degree splitting graph, k - regular adjacency vertex, $\mathrm{k}$ - regular adjacency graph.

\section{Introduction}

Only finite, simple, undirected graphs are considered in this paper. For notations and terminology, we follow [10]. The degree of a vertex $\mathrm{v}$ is denoted by $\mathrm{d}(\mathrm{v})$. Let $\mathrm{V}_{\mathrm{i}}$ denote the set of all vertices of degree i. A graph G is said to be $r$-regular, if every vertex of $\mathrm{G}$ has degree $r$. For $\mathrm{r} \neq \mathrm{k}$, a graph $\mathrm{G}$ is said to be $(r, k)-$ biregular if $\mathrm{d}(\mathrm{v})$ is either $r$ or $k$ for any vertex $v$ in $G$. A $1-$ factor of $G$ is a $1-$ regular spanning subgraph of $G$ and it is denoted by F.

For any vertex $\mathrm{v} \in \mathrm{V}(\mathrm{G})$, the open neighbourhood $\mathrm{N}(\mathrm{v})$ of $\mathrm{v}$ is the set of all vertices adjacent to $\mathrm{v}$. That is, $\mathrm{N}(\mathrm{v})=\{\mathrm{u} \in \mathrm{V}(\mathrm{G}) / \mathrm{uv} \in \mathrm{E}(\mathrm{G})\}$. The closed neighbourhood of $\mathrm{v}$ is defined by $N[v]=N(v) \cup\{v\}$. The join of two graphs $G_{1}$ and $G_{2}$ is denoted by $G_{1} \vee G_{2}$. In 
a graph $G(V, E)$, let $V_{i}=\{v \in V / d(v)=i\}$. Note that in an $r$ - regular graph $G, V_{r}=V(G)$ and $V_{i}=\phi$ for any $i \neq r$. A vertex $v$ in $G$ is called a distinguished vertex of $G$ if $v$ is the only vertex in $\mathrm{G}$ with degree $\mathrm{d}(\mathrm{v})$.

A vertex $\mathrm{v}$ is said to be a $k$ - regular adjacency vertex (or simply a $\mathrm{k}$ - RA vertex) if $\mathrm{d}(\mathrm{u})=\mathrm{k}$ for all $\mathrm{u} \in \mathrm{N}(\mathrm{v})$. A vertex is called an $R A$ vertex if it is a $\mathrm{k}-\mathrm{RA}$ vertex for some $\mathrm{k}$ 21. A graph $G$ in which every vertex is an $R A$ vertex is said to be an $R A$ graph. Obviously regular graphs and complete bipartite graphs are RA graphs.

Analysing a graph by varying its vertex set and edge set is an interesting and well worked branch of research in graph theory. The studies on antipodal graphs and radial graphs $[1,2,3,11,12]$ are examples in which the edge set of a graph varies itself. While studies based on the minimum number of vertices to be added to a graph [9] to attain a special property vary both of its vertex set and edge set. This branch of research has credited its account with one when Sampath Kumar and Walikar introduced the concept of splitting graph [14] of a graph. This concept resembles the method of taking clone of each vertex in a graph.

The definition of splitting graph is given as follows:

The graph $S(G)$ obtained from $G$, by taking a new vertex $v^{\prime}$ for every vertex $v \in V$ and joining $v^{\prime}$ to all vertices of $G$ adjacent to $v$, is called a splitting graph of $G$. As an illustration, a graph $G$ with its splitting graph $S(G)$ is shown in Figure 1.

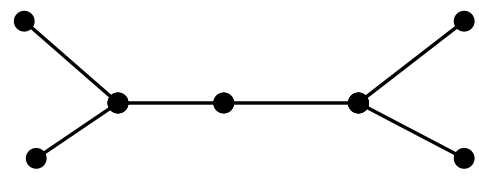

G

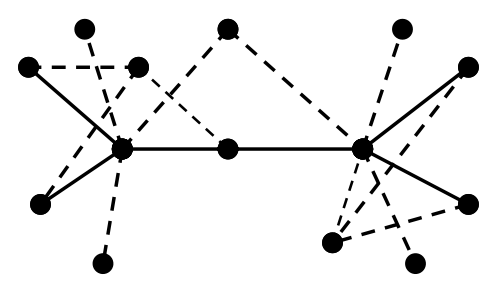

S(G)

Figure 1 
The properties of splitting graphs have been studied and the necessary and sufficient condition for a graph to be a splitting graph has been established in [14]. In fact, it has been proved that,

Result 1.1 [14] A graph $G$ is a splitting graph if and only if $V(G)$ can be partitioned into two sets $V_{1}$ and $V_{2}$ such that there exists a bijective mapping f from $V_{1}$ to $V_{2}$ and $N(f(v))$ $=\mathrm{N}(\mathrm{v}) \cap \mathrm{V}_{1}$, for any $\mathrm{v} \in \mathrm{V}_{1}$.

On a similar line, recently instead of adding a clone for every vertex, a method of adding complement to every vertex has been introduced and studied for its properties [4].

Let $G$ be a graph with vertex set $\left\{v_{1}, v_{2}, \ldots, v_{n}\right\}$. The cosplitting graph $C S(G)$ is the graph obtained from $G$, by adding a new vertex $w_{i}$ for each vertex $v_{i}$ and joining $w_{i}$ to all vertices which are not adjacent to $v_{i}$ in $G$.

For instance, a graph $G$ and its cosplitting graph $C S(G)$ are shown in Figure 2.

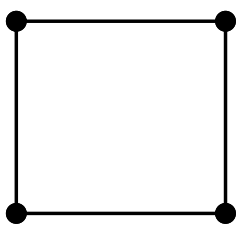

G

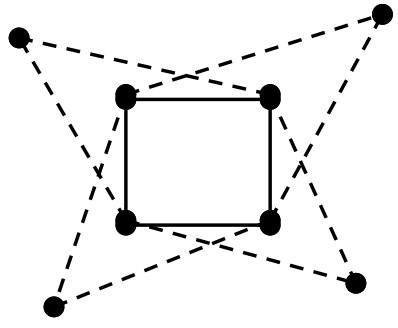

CS(G)

Figure 2

In [4], a necessary and sufficient condition for a graph to be a cosplitting graph has been given. And the graphs for which the splitting graph and the cosplitting graph are isomorphic have been characterised.

This branch spreads out its wings further with the introduction of degree splitting graph by Ponraj and Somasundaram [13].

The degree splitting graph $\mathrm{DS}(\mathrm{G})$ of a graph $\mathrm{G}$ can be defined as follows: For a graph $\mathrm{G}=(\mathrm{V}, \mathrm{E})$, the degree splitting graph $\mathrm{DS}(\mathrm{G})$ is obtained from $\mathrm{G}$, by adding a new 
vertex $\mathrm{w}_{\mathrm{i}}$ for each partition $\mathrm{V}_{\mathrm{i}}$ that contains at least two vertices and joining $\mathrm{w}_{\mathrm{i}}$ to each vertex of $V_{i}$.

For example, a graph $G$ and its degree splitting graph $D S(G)$ are shown in Figure 3.

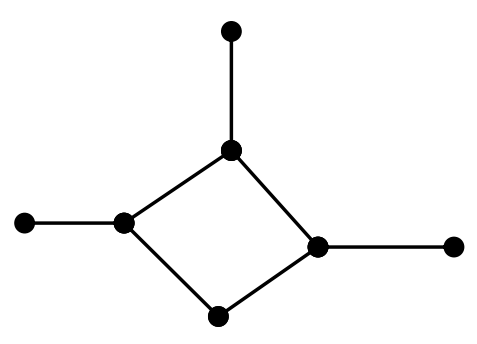

G

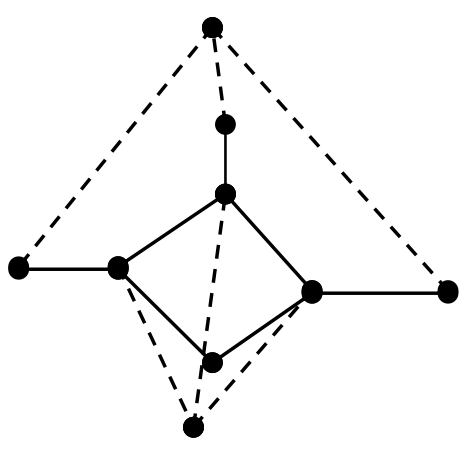

DS(G)

\section{Figure 3}

It is easy to note that, if $G$ is regular, then $D S(G)$ is nothing but $G \vee K_{1}$. And trivial graph is the only graph for which the degree splitting graph is isomorphic to itself. Also every graph is an induced subgraph of its own degree splitting graph. In addition, the following results have been proved in [5].

Let $K_{n, 2 n+1}$ be the complete bipartite graph with bipartition $(X, Y)$ where $X=\left\{v_{1}, v_{2}\right.$, $\left.\ldots, \mathrm{v}_{n}\right\}$ and $Y=\left\{\mathrm{w}_{1}, \mathrm{w}_{2}, \ldots, \mathrm{w}_{2 \mathrm{n}+1}\right\}$. Then $\mathrm{K}_{\mathrm{n}, 2 \mathrm{n}+1}^{*}$ is the graph obtained from $\mathrm{K}_{\mathrm{n}, 2 \mathrm{n}+1}$ by deleting the edges $v_{i} W_{2 i-1}$ and $v_{i} W_{2 i}$ for all $i, 1 \leq i \leq n$. For example $K_{2,5}^{*}$ is shown in Figure 4 .

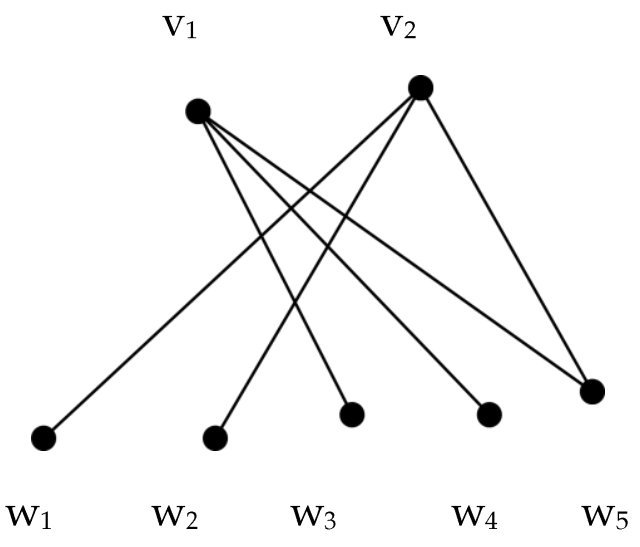

Figure 4 
Theorem A The degree splitting graph $\mathrm{DS}(\mathrm{G})$ is regular if and only $G \cong K_{r}, r \geq 1$ or $\left(K_{2 k}-F\right) \vee K_{1}$, where $F$ is a $1-$ factor of $K_{2 k}$ and $k \geq 2$.

Theorem B Let $G$ be a graph. Then $D S(G)$ is a biregular RA graph if and only if $G \cong K_{1, n}$ or $\mathrm{K}_{\mathrm{n}, 2 \mathrm{n}+1}^{*}$.

Theorem C Any connected RA graph is either a regular graph or a biregular bipartite graph.

The definition of the degree splitting graph has inspired us very much as it resembles the process of assigning representatives for people having same qualities from the society of diverse qualities. It may also be compared to uniting systems according to their common nature in a network. Hence studying the properties of degree splitting graphs surely yield results of practical importance.

In this paper, we characterize the graphs for which degree splitting graphs are trees or unicyclic. We discuss the necessary conditions for a graph to be a degree splitting graph for some graph and we develop an algorithm to check whether the given graph is a degree splitting graph or not. Also for any $n \geq 2$, we construct $n$ non isomorphic graphs, $G_{1}, G_{2}, \ldots, G_{n}$ having isomorphic degree splitting graph. We establish some necessary conditions for the existence of non isomorphic graphs with isomorphic degree splitting graph.

Further a study on distance in degree splitting graphs has been carried out in [7]. And studies on varieties of splitting graphs can be found in [6] and [8].

\section{Construction of non isomorphic graphs with same degree splitting graph:}

It is obvious that every graph has its own degree splitting graph. On the other hand, here we discuss about the converse of the above statement, that is, whether every degree splitting graph is a degree splitting graph of a unique graph. Thinking of this line, there arises a natural question in our mind that "Do there exist different groups such that after assigning representatives for similar nodes they look similar?". Or in 
graph theoretical words, "Can we think of the existence of two or more non isomorphic graphs with similar degree splitting graph?". To our surprise, the answer is 'yes'.

It is easy to note that $\mathrm{G} \cong \mathrm{H}$ implies $\mathrm{DS}(\mathrm{G}) \cong \mathrm{DS}(\mathrm{H})$. But the converse is not true. That is, we can find two non isomorphic graphs $G_{1}$ and $G_{2}$ such that $D S\left(G_{1}\right) \cong D S\left(G_{2}\right)$. For example, consider the non isomorphic graphs $G_{1}$ and $G_{2}$ shown in Figure 5. But $\mathrm{DS}\left(\mathrm{G}_{1}\right) \cong \mathrm{DS}\left(\mathrm{G}_{2}\right)$.

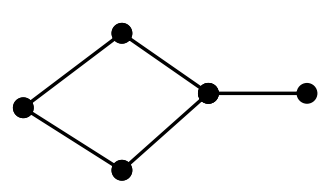

$\mathrm{G}_{1}$

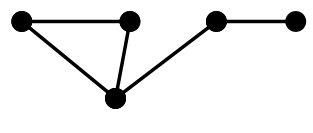

$\mathrm{G}_{2}$

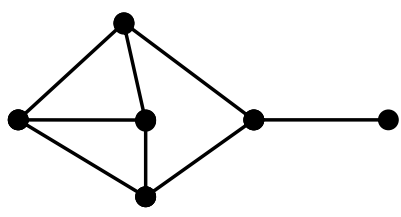

$\mathrm{DS}\left(\mathrm{G}_{1}\right) \cong \mathrm{DS}\left(\mathrm{G}_{2}\right)$

Figure 5

In fact, for given $n \geq 2$, we can find $n$ non isomorphic graphs $G_{1}, G_{2}, \ldots, G_{n}$, with the same degree splitting graph, the existence of which is proved in the following theorem:

Theorem 2.1 For any $n \geq 2$, there are $n$ non isomorphic graphs $G_{1}, G_{2}, \ldots$, $G_{n}$ whose degree splitting graphs are all isomorphic.

Proof If $n=2$, then we have done. Therefore assume that $n \geq 3$. For any $i, 1 \leq i \leq n-1$, we construct a graph $\mathrm{G}_{\mathrm{i}}$ as follows:

Vertex set $V\left(G_{i}\right)$ of $G_{i}$ consists of 3n-1 vertices

$u_{1}^{i}, u_{2}^{i}, v_{1}^{i}, v_{2}^{i}, \ldots,, v_{i-1}^{i}, v_{i+1}^{i}, \ldots, v_{n-1}^{i}, w_{1}^{i}, w_{2}^{i}, \ldots, w_{n-1}^{i}, x_{1}^{i}, x_{2}^{i} \ldots, x_{n-1}^{i}, x_{n}^{i}$ and the edge set $E\left(G_{i}\right)=\left\{u_{1}^{i} v_{j}^{i} / 1 \leq j \leq n-1 ; 1=1,2 ; j \neq i\right\} \cup\left\{u_{1}^{i} w_{j}^{i} / 1 \leq j \leq n-1 ; 1=1,2\right\} \cup\left\{v_{k}^{i} v_{1}^{i} / 1 \leq k \leq\right.$ $\mathrm{n}-1 ; 1 \leq 1 \leq \mathrm{n}-1 ; \mathrm{k} \neq \mathrm{i} ; 1 \neq \mathrm{i} ; \mathrm{k} \neq \mathrm{l}\} \cup\left\{\mathrm{v}_{\mathrm{k}}^{\mathrm{i}} \mathrm{w}_{1}^{\mathrm{i}} / 1 \leq \mathrm{k} \leq \mathrm{n}-1 ; 1 \leq 1 \leq \mathrm{n}-1 ; \mathrm{k} \neq \mathrm{i} ; \mathrm{k} \neq \mathrm{l}\right\} \cup$ $\left\{w_{j}^{i} x_{k}^{i} / 1 \leq j \leq n-1 ; 1 \leq k \leq n-1 ; j \neq k\right\} \cup\left\{x_{1}^{i} x_{j}^{i} / 1 \leq 1 \leq\left\lfloor\frac{n-1}{2}\right\rfloor ; i+1 \leq j \leq n-\right.$ i $\} \cup\left\{x_{\left[\frac{n+1}{2}\right]}^{i} x_{n}^{i}\right\}$. 
Clearly, $u_{1}^{\mathrm{i}}, \mathrm{u}_{2}^{\mathrm{i}}, \mathrm{v}_{1}^{\mathrm{i}}, \mathrm{v}_{2}^{\mathrm{i}}, \ldots, \mathrm{v}_{\mathrm{i}-1}^{\mathrm{i}}, \mathrm{v}_{\mathrm{i}+1}^{\mathrm{i}}, \ldots, \mathrm{v}_{\mathrm{n}-1}^{\mathrm{i}}, \mathrm{w}_{1}^{\mathrm{i}}, \mathrm{w}_{2}^{\mathrm{i}}, \ldots, \mathrm{w}_{\mathrm{i}-1}^{\mathrm{i}}, \mathrm{w}_{\mathrm{i}+1}^{\mathrm{i}}, \ldots, \mathrm{w}_{\mathrm{n}-1}^{\mathrm{i}}$ are all of degree $2 n-3 . w_{i}^{i}$ is the only vertex of degree $2(n-1)$. For $j=1,2, \ldots, n$, the degrees of $x_{j}^{j}$ s are respectively, $2 n-4,2 n-5, \ldots, n+\left\lfloor\frac{n-1}{2}\right\rfloor-1, n+\left\lfloor\frac{n-1}{2}\right\rfloor-1, n+\left\lfloor\frac{n-1}{2}\right\rfloor-2, \ldots, n+1, n, n-1,1$.

Finally, the graph $G_{n}$ is constructed as follows:

$\mathrm{V}\left(\mathrm{G}_{\mathrm{n}}\right)=\left\{\mathrm{v}_{1}^{\mathrm{n}}, \mathrm{v}_{2}^{\mathrm{n}}, \ldots, \mathrm{v}_{\mathrm{n}-1}^{\mathrm{n}}, \mathrm{w}_{1}^{\mathrm{n}}, \mathrm{w}_{2}^{\mathrm{n}}, \ldots, \mathrm{w}_{\mathrm{n}-1}^{\mathrm{n}}, \mathrm{w}_{\mathrm{n}}^{\mathrm{n}}, \mathrm{x}_{1}^{\mathrm{n}}, \mathrm{x}_{2}^{\mathrm{n}} \ldots, \mathrm{x}_{\mathrm{n}-1}^{\mathrm{n}}, \mathrm{y}^{\mathrm{n}}\right\}$

$\mathrm{E}\left(\mathrm{G}_{\mathrm{n}}\right)=\left\{\mathrm{w}_{\mathrm{n}}^{\mathrm{n}} \mathrm{v}_{\mathrm{j}}^{\mathrm{n}}, \mathrm{w}_{\mathrm{n}}^{\mathrm{n}} \mathrm{w}_{\mathrm{j}}^{\mathrm{n}} / 1 \leq \mathrm{j} \leq \mathrm{n}-1\right\} \cup\left\{\mathrm{v}_{\mathrm{k}}^{\mathrm{n}} \mathrm{v}_{1}^{\mathrm{n}} / 1 \leq \mathrm{k} \leq \mathrm{n}-1,1 \leq 1 \leq \mathrm{n}-1, \mathrm{k} \neq 1\right\} \cup$ $\left\{\mathrm{v}_{\mathrm{k}}^{\mathrm{n}} \mathrm{w}_{1}^{\mathrm{n}} / 1 \leq \mathrm{k} \leq \mathrm{n}-1,1 \leq 1 \leq \mathrm{n}-1, \mathrm{k} \neq 1\right\} \cup\left\{\mathrm{w}_{\mathrm{j}}^{\mathrm{n}} \mathrm{x}_{\mathrm{k}}^{\mathrm{n}} / 1 \leq \mathrm{j} \leq \mathrm{n}-1,1 \leq \mathrm{k} \leq \mathrm{n}-1, \mathrm{j} \neq \mathrm{k}\right\}$ $\left.\cup\left\{x_{i}^{n} x_{j}^{n} / 1 \leq i \leq \mid \frac{n-1}{2}\right], i+1 \leq j \leq n-i\right\} \cup\left\{x_{\left[\frac{n+1}{2}\right]}^{n} x_{n}^{i}\right\}$. Here $w_{n}^{n}$ is the only vertex of degree $2 n-2$ while all $v_{j}^{n \prime}$ s and $w_{j}^{n}$ 's are of degree $2 n-3$ where $1 \leq j \leq n-1$.

First we claim that all $\mathrm{G}_{\mathrm{i}}$ 's are non isomorphic.

Clearly for each $i, 1 \leq i \leq n, G_{i}$ has only one vertex $w_{i}^{i}$ with degree $2 n-2$. By our construction, each $G_{i}$ has unique induced subgraph generated by $N\left(w_{i}^{i}\right)$. That is, < $\mathrm{N}\left[\mathrm{w}_{\mathrm{i}}^{\mathrm{i}}\right]>¥<\mathrm{N}\left[\mathrm{w}_{\mathrm{j}}^{\mathrm{j}}\right]>$, for all $\mathrm{i} \neq \mathrm{j}, 1 \leq \mathrm{i}, \mathrm{j} \leq \mathrm{n}$ and hence $\mathrm{G}_{\mathrm{i}}^{\prime}$ s are all non isomorphic.

Now we prove that $D S\left(G_{i}\right) \cong D S\left(G_{i}\right)$, for $1 \leq i, j \leq n-1$.

The vertex set $V\left(G_{i}\right)$ of any $G_{i}$ can be partitioned as $V\left(G_{i}\right)=V_{1} \cup \ldots \cup V_{2(n-1)}$, such that $V_{i}$ contains the vertices of degree $i$. In such partition, $V_{n+\left\lfloor\frac{n-1}{2}\right\rfloor-1}$ and $V_{2 n-3}$ have more than one vertex. Therefore for any $G_{i}$, in the construction of $D S\left(G_{i}\right)$ two new vertices $\left\{\mathrm{y}_{\mathrm{n}+\left[\frac{\mathrm{n}-1}{2}\right]-1}, \mathrm{y}_{2 \mathrm{n}-3}\right\}$ are introduced. Define $\mathrm{f}: \mathrm{V}\left(\mathrm{DS}\left(\mathrm{G}_{\mathrm{i}}\right)\right) \rightarrow \mathrm{V}\left(\mathrm{DS}\left(\mathrm{G}_{\mathrm{j}}\right)\right)$ as follows:

$f\left(u_{1}^{i}\right)=u_{1}^{j}, 1=1,2 ; f\left(v_{k}^{i}\right)=v_{k^{\prime}}^{j}, k \neq j, k \neq i, k=1,2, \ldots, n-1 ; f\left(w_{1}^{i}\right)=w_{1}^{j}, 1=1,2, \ldots, n-1$;

$\mathrm{f}\left(\mathrm{x}_{1}^{\mathrm{i}}\right)=\mathrm{x}_{1^{\mathrm{j}}}^{\mathrm{j}}, \quad 1=1,2, \ldots, \mathrm{n} ; \mathrm{f}\left(\mathrm{y}_{1}^{\mathrm{i}}\right)=\mathrm{y}_{1^{\prime}}^{\mathrm{j}} 1=2 \mathrm{n}-3, \mathrm{n}+\left[\frac{\mathrm{n}-1}{2}\right]-1$ and $\mathrm{f}\left(\mathrm{v}_{\mathrm{j}}^{\mathrm{i}}\right)=\mathrm{v}_{\mathrm{i}}^{\mathrm{j}}$.

Then $\mathrm{f}$ is clearly an isomorphism from $\mathrm{DS}\left(\mathrm{G}_{\mathrm{i}}\right)$ to $\mathrm{DS}\left(\mathrm{G}_{\mathrm{j}}\right)$. Thus $\mathrm{DS}\left(\mathrm{G}_{\mathrm{i}}\right) \cong \mathrm{DS}\left(\mathrm{G}_{\mathrm{j}}\right)$, for all $\mathrm{i}$ and $j, 1 \leq i, j \leq n-1$. Finally, it is enough to show that $D S\left(G_{1}\right) \cong D S\left(G_{n}\right)$. 

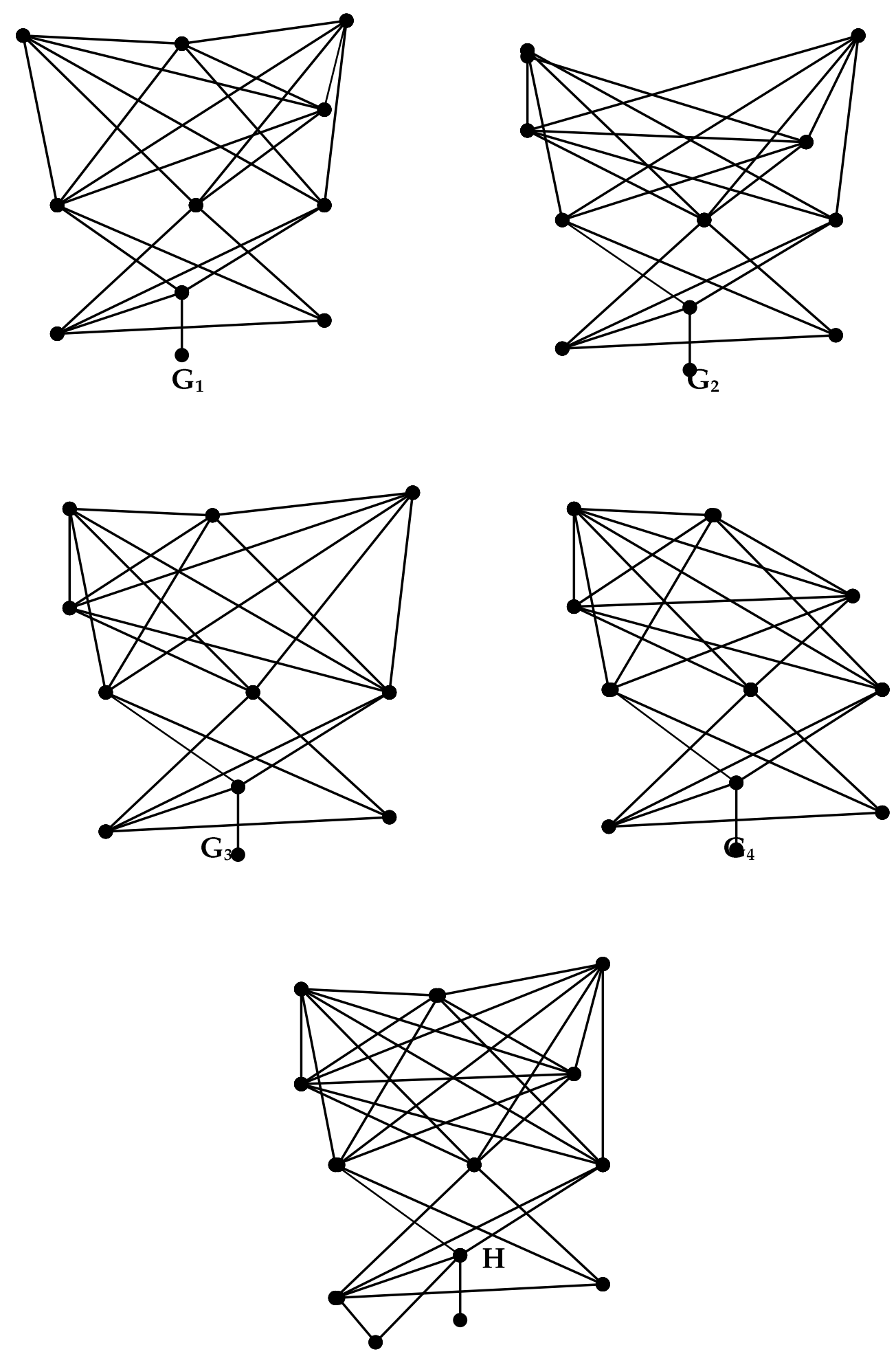

Figure 6 
Let $\mathrm{g}: \mathrm{V}\left(\mathrm{DS}\left(\mathrm{G}_{1}\right)\right) \rightarrow \mathrm{V}\left(\mathrm{DS}\left(\mathrm{G}_{\mathrm{n}}\right)\right)$ be defined as follows:

$$
\mathrm{g}\left(\mathrm{u}_{1}^{1}\right)=\mathrm{w}_{\mathrm{n}}^{\mathrm{n}} ; \mathrm{g}\left(\mathrm{u}_{2}^{1}\right)=\mathrm{y}_{2 \mathrm{n}-3^{\mathrm{n}}} ; \mathrm{g}\left(\mathrm{v}_{\mathrm{k}}^{1}\right)=\mathrm{v}_{\mathrm{k}}^{\mathrm{n}} ; \mathrm{g}\left(\mathrm{w}_{\mathrm{k}}^{1}\right)=\mathrm{w}_{\mathrm{k}}^{\mathrm{n}} ; \mathrm{g}\left(\mathrm{x}_{\mathrm{k}}^{1}\right)=\mathrm{x}_{\mathrm{k}}^{\mathrm{n}}, \mathrm{k}=1,2, \ldots, \mathrm{n}-1 ;
$$

$\mathrm{g}\left(\mathrm{y}_{\mathrm{n}+\left\lfloor\frac{\mathrm{n}-1}{2}\right\rfloor-1}^{1}\right)=\mathrm{y}_{\mathrm{n}+\left\lfloor\frac{\mathrm{n}-1}{2}\right\rfloor-1}^{\mathrm{n}}$. Again $\mathrm{g}$ is clearly an isomorphism from $\mathrm{DS}\left(\mathrm{G}_{1}\right)$ to $\mathrm{DS}\left(\mathrm{G}_{\mathrm{n}}\right)$ and therefore $D S\left(G_{i}\right) \cong D S\left(G_{n}\right)$, for any $i, 1 \leq i \leq n-1$. Thus we have constructed $n$ non isomorphic graphs $G_{1}, G_{2}, \ldots, G_{n}$ with same degree splitting graph. For example, when $n$ $=4$, the four non isomorphic graphs $\mathrm{G}_{1}, \mathrm{G}_{2}, \mathrm{G}_{3}, \mathrm{G}_{4}$ and their degree splitting graph $\mathrm{H}$ are shown in Figure 6.

It is also true that there are graphs which are degree splitting graphs of unique graphs. Therefore in this chapter, we concentrate on the conditions needed for the existence of non isomorphic graphs to have isomorphic degree splitting graph. Let us discuss about the various conditions under which two graphs have the same degree splitting graph. The following theorem discusses one such condition.

Theorem 2.2 In a graph $G$ with $\left|V_{k}\right| \geq 2$, for some $k \geq 2$, if there exists a distinguished vertex $v$ such that $N(v)=V_{k} \cup\{w\}$, where $w$ is the distinguished vertex of degree $k+1$ and $\left|V_{\left|V_{k}\right|}\right|=0$, then there exists a graph $H$ such that $G ¥ H$ and $D S(G) \cong D S(H)$.

Proof Let $\mathrm{G}$ be any graph. Let $\mathrm{w}$ be the distinguished vertex of $\mathrm{G}$ with degree $\mathrm{k}+1$. Suppose $\mathrm{v}$ is another distinguished vertex of $\mathrm{G}$ such that $\mathrm{N}(\mathrm{v})=\mathrm{V}_{\mathrm{k}} \cup\{\mathrm{w}\}$. Take $\left|\mathrm{V}_{\mathrm{k}}\right|=\mathrm{a}$ in $\mathrm{G}$. Then clearly $\mathrm{d}_{\mathrm{G}}(\mathrm{v})=\mathrm{a}+1$. Let $\mathrm{V}(\mathrm{G})=\left\{\mathrm{v}, \mathrm{w}, \mathrm{v}_{1}, \mathrm{v}_{2}, \ldots, \mathrm{v}_{\mathrm{n}-2}\right\}$. Consider the degree splitting graph DS(G) of $G$. Let $\mathfrak{u}_{1}, \mathrm{u}_{2}, \ldots, \mathrm{u}_{\mathrm{m}}$ be the newly added vertices in $\mathrm{DS}(\mathrm{G})$. Then $\mathrm{d}^{*}(\mathrm{v})=\mathrm{d}_{\mathrm{G}}(\mathrm{v}), \mathrm{d}^{*}(\mathrm{w})=\mathrm{d}_{\mathrm{G}}(\mathrm{w})$ and $\mathrm{d}_{\mathrm{G}}\left(\mathrm{v}_{\mathrm{i}}\right) \leq \mathrm{d}^{*}\left(\mathrm{v}_{\mathrm{i}}\right) \leq \mathrm{d}_{\mathrm{G}}\left(\mathrm{v}_{\mathrm{i}}\right)+1$. Since $\left|\mathrm{V}_{\mathrm{k}}\right| \geq 2$, let $\mathrm{u}_{\mathrm{j}}$ be the newly added vertex in $D S(G)$ for some $j, 1 \leq j \leq m$, corresponding to $V_{k}$.

Let $H$ be the induced subgraph of $D S(G)$ induced by $\left\{v_{1}, v_{2}, \ldots, v_{n-2}, w, u_{j}\right\}$. We claim that $\mathrm{G} ¥ \mathrm{H}$ and $\mathrm{DS}(\mathrm{G}) \cong \mathrm{DS}(\mathrm{H})$. 
We know that $d^{*}\left(u_{j}\right)=\left|V_{k}\right|=a$ in $D S(G)$. Clearly in DS(G), $v \notin N\left(u_{j}\right)$ and for any $\mathrm{u}_{\mathrm{i}}, \mathrm{i} \neq \mathrm{j}$ and $1 \leq \mathrm{i} \leq \mathrm{m}, \mathrm{u}_{\mathrm{i}} \notin \mathrm{N}\left(\mathrm{u}_{\mathrm{j}}\right)$. Therefore $\mathrm{d}_{\mathrm{H}}\left(\mathrm{u}_{\mathrm{i}}\right)=\mathrm{a}$. But given that $\left|\mathrm{V}_{\mathrm{a}}\right|=0$ in $\mathrm{G}$. Hence we can conclude that $\mathrm{G} ¥ \mathrm{H}$.

Clearly in $\mathrm{G},\left|V_{a}\right|=0,\left|V_{a+1}\right|=1,\left|V_{\mathrm{k}+1}\right|=1$. Also $\mathrm{v}$ is a neighbour of $\mathrm{w}$ in $\mathrm{G}$. This means that $\mathrm{d}_{\mathrm{H}}(\mathrm{w})=\mathrm{d}_{\mathrm{G}}(\mathrm{w})-1=\mathrm{k}$. Therefore we get in $\mathrm{H},\left|V_{a}\right|=1,\left|V_{a+1}\right|=0,\left|V_{\mathrm{k}+1}\right|=0$. The remaining members $V_{i}$ in the vertex set partition are the same in $G$ and $H$. And so $\mathrm{DS}(\mathrm{H})$ has the same number of newly added vertices as that of in DS(G). Let them be $\mathrm{w}_{1}, \mathrm{w}_{2}, \ldots, \mathrm{w}_{\mathrm{m}}$ and without loss of generality, let $\mathrm{w}_{\mathrm{i}}$ correspond to the set for which $\mathrm{u}_{\mathrm{i}}$ corresponds to in $\mathrm{DS}(\mathrm{G})$. Then $\mathrm{w}_{\mathrm{j}}$ is of degree $\mathrm{a}+1$ and hence it is a distinguished vertex in $\mathrm{DS}(\mathrm{H})$.

Now define a mapping $f$ from the vertex set of $D S(G)$ to that of $D S(H)$ by $f(v)=w_{j}, f\left(u_{t}\right)$ $=\mathrm{w}_{\mathrm{t}}, 1 \leq \mathrm{t} \leq \mathrm{m}$ and $\mathrm{t} \neq \mathrm{j}, \mathrm{f}\left(\mathrm{u}_{\mathrm{j}}\right)=\mathrm{u}_{\mathrm{j}}, \mathrm{f}(\mathrm{w})=\mathrm{w}, \mathrm{f}\left(\mathrm{v}_{\mathrm{s}}\right)=\mathrm{v}_{\mathrm{s}}, 1 \leq \mathrm{s} \leq \mathrm{n}-2$. We can easily verify $\mathrm{f}$ to be an isomorphism. Therefore $\mathrm{DS}(\mathrm{G}) \cong \mathrm{DS}(\mathrm{H})$. Hence the theorem.

For example, a graph $\mathrm{G}$ with the required conditions and the corresponding graph $\mathrm{H}$ and their isomorphic degree splitting graph are shown in Figure 7. 


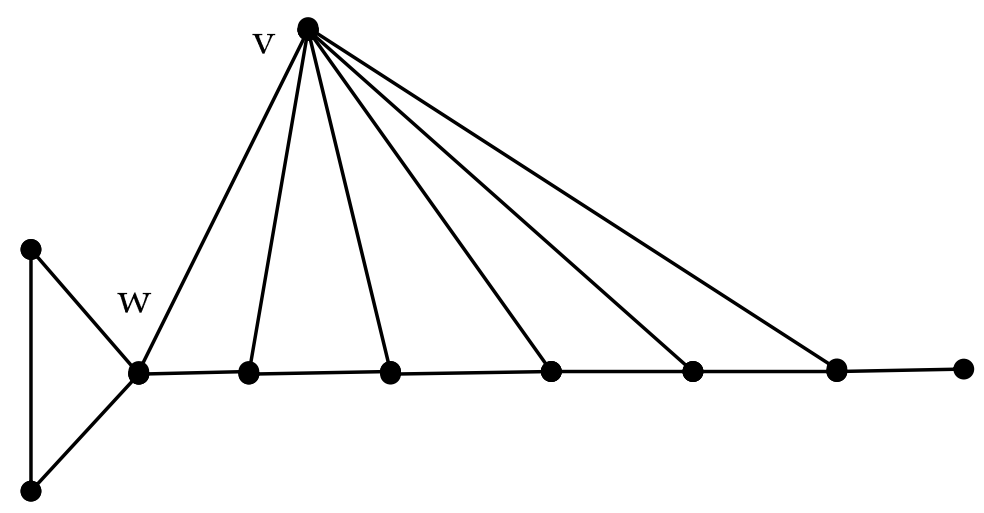

G

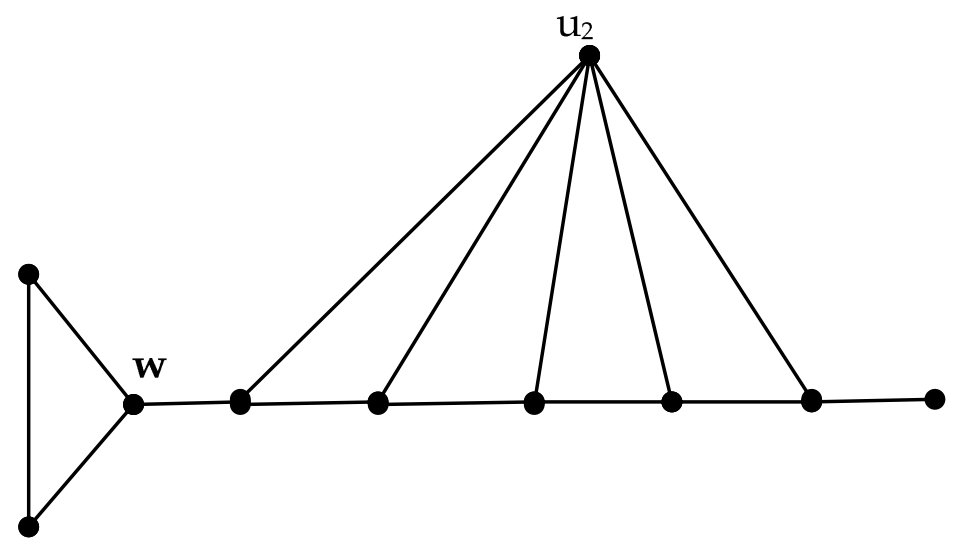

H

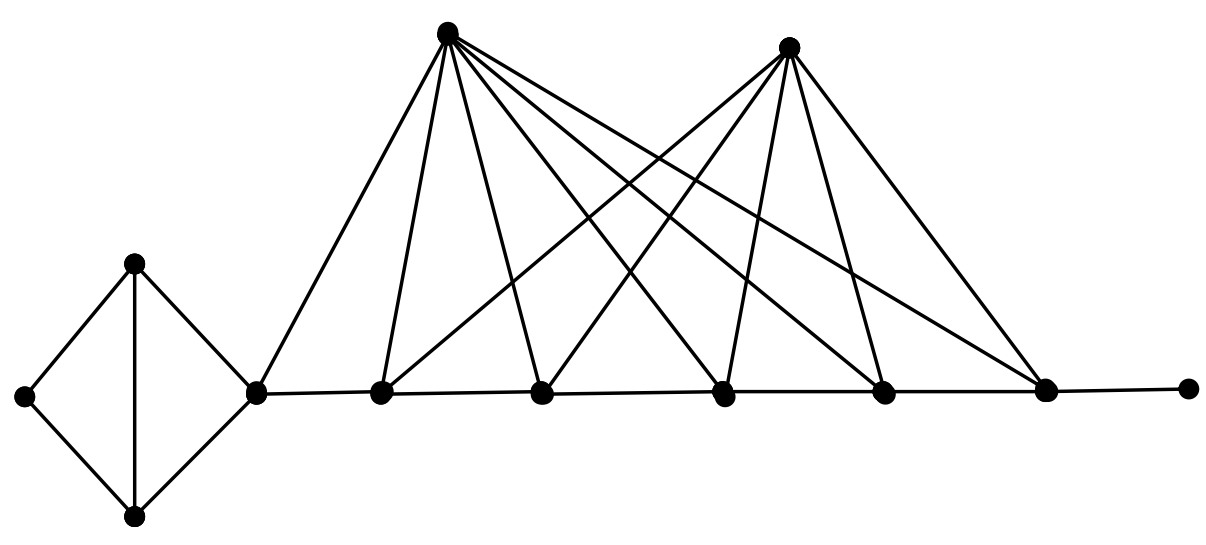

$\mathrm{DS}(\mathrm{G}) \cong \mathrm{DS}(\mathrm{H})$

Figure 7 
The next theorem discusses a similar condition for the existence of non isomorphic graphs with same degree splitting graph.

Theorem 2.3 In a graph G with $\left|V_{k}\right|>2$, for some $k \geq 2$ and $\left|V_{k+1}\right|=0=\left|V_{\left|V_{k}\right|}\right|$, if there exists a distinguished RA vertex $v$ such that $N(v)=V_{k}-\{u\}$, for some $u \in V_{k}$, then there exists a graph $H$ such that $G ¥ H$ and $D S(G) \cong D S(H)$.

Proof Let $\mathrm{G}$ be any graph. Assume that $\left|V_{k}\right|>2$. Take $\left|V_{k}\right|=a$ in $G$. Let $u$ be a vertex of degree $\mathrm{k}$ in $\mathrm{G}$ and let $\mathrm{v}$ be a distinguished RA vertex in $\mathrm{G}$ such that $\mathrm{N}(\mathrm{v})=\mathrm{V}_{\mathrm{k}}-\{\mathrm{u}\}$. Now $\mathrm{d}_{\mathrm{G}}(\mathrm{v})=\mathrm{a}-1$.

Let $\mathrm{V}(\mathrm{G})=\left\{\mathrm{u}, \mathrm{v}, \mathrm{v}_{1}, \mathrm{v}_{2}, \ldots, \mathrm{v}_{\mathrm{n}-2}\right\}$. Let $\mathrm{DS}(\mathrm{G})$ be the degree splitting graph of $\mathrm{G}$ with the newly added vertices $\mathrm{u}_{1}, \mathrm{u}_{2}, \ldots, \mathrm{u}_{\mathrm{m}}$.

And since $\left|V_{k}\right|>2$, let $u_{j}$ correspond to $V_{k}$, for some $j, 1 \leq j \leq m$. Now in DS(G), $d^{*}(u)=d(u)+1=k+1$ and $d^{*}\left(u_{j}\right)=a$. Since $v$ is a distinguished vertex in $G, d^{*}(v)=$ $\mathrm{d}_{\mathrm{G}}(\mathrm{v})=\mathrm{a}-1$.

Consider the induced subgraph $H$ of $D S(G)$ induced by $\left\{v_{1}, v_{2}, \ldots, v_{n-2}, u, u_{j}\right\}$. Now we prove that $\mathrm{H}$ is not isomorphic to $\mathrm{G}$ but $\mathrm{DS}(\mathrm{G}) \cong \mathrm{DS}(\mathrm{H})$.

It is clear that $\mathrm{V}(\mathrm{H})=(\mathrm{V}(\mathrm{G})-\{\mathrm{v}\}) \cup\left\{\mathrm{u}_{\mathrm{j}}\right\}$. Hence for any $\mathrm{v}_{\mathrm{i}}, 1 \leq \mathrm{i} \leq \mathrm{n}-2, \mathrm{~d}_{\mathrm{G}}\left(\mathrm{v}_{\mathrm{i}}\right)=$ $d_{H}\left(v_{i}\right)$. Also $d_{H}\left(u_{j}\right)=a, d_{H}(u)=d_{G}(u)+1=k+1$.

Since $\mathrm{G}$ does not contain any vertex of degree $a, u_{j}$ is a distinguished vertex of degree a in $\mathrm{H}$. Hence we can conclude that $\mathrm{G} ¥ \mathrm{H}$.

Now we consider DS(H). Clearly $\left|V_{a-1}\right|=1,\left|V_{a}\right|=0,\left|V_{\mathrm{k}+1}\right|=0$ in G. Since $\mathrm{v} \notin$ $\mathrm{H}$, we have $\left|V_{a-1}\right|=0,\left|V_{a}\right|=1,\left|\mathrm{~V}_{\mathrm{k}+1}\right|=1$ in $\mathrm{H}$.

The remaining members $V_{i}$ in the vertex set partition are the same in $G$ and $H$. And so DS(H) has the same number of newly added vertices as that of in DS(G).

Let them be $\mathrm{w}_{1}, \mathrm{w}_{2}, \ldots, \mathrm{w}_{\mathrm{m}}$ and without loss of generality, let $\mathrm{w}_{\mathrm{i}}$ correspond to the set for which $\mathrm{u}_{\mathrm{i}}$ corresponds to in $\mathrm{DS}(\mathrm{G})$. Then $\mathrm{w}_{\mathrm{j}}$ is a distinguished vertex of degree a 1.

Now define a mapping $\mathrm{f}$ from the vertex set of $\mathrm{DS}(\mathrm{G})$ to that of $\mathrm{DS}(\mathrm{H})$ by $\mathrm{f}(\mathrm{v})=$ $w_{j}, f\left(u_{t}\right)=w_{t}, 1 \leq t \leq m$ and $t \neq j, f\left(u_{j}\right)=u_{j}, f(u)=u, f\left(v_{s}\right)=v_{s}, 1 \leq s \leq n-2$. 
We can easily verify that $\mathrm{f}$ is an isomorphism. Hence $\mathrm{DS}(\mathrm{G}) \cong \mathrm{DS}(\mathrm{H})$.

For example, a graph $G$ with the required conditions and the corresponding graph $\mathrm{H}$ constructed and their isomorphic degree splitting graph are shown in Figure 8.

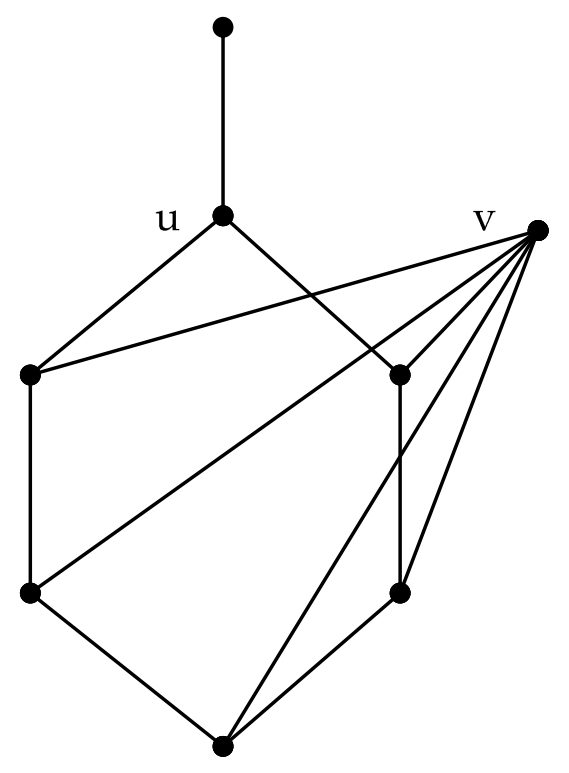

G

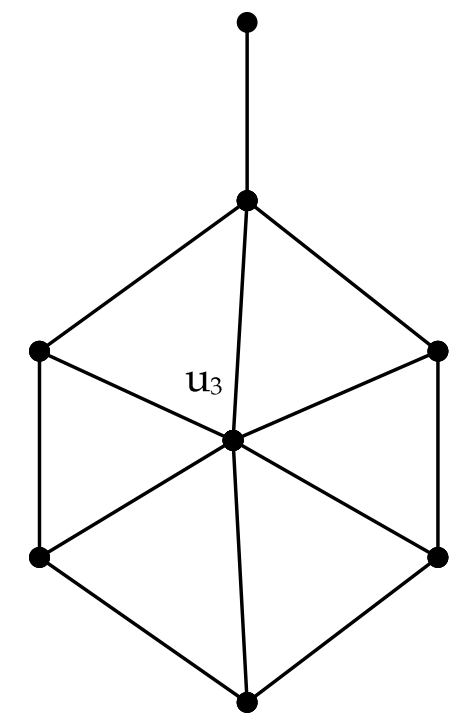

H

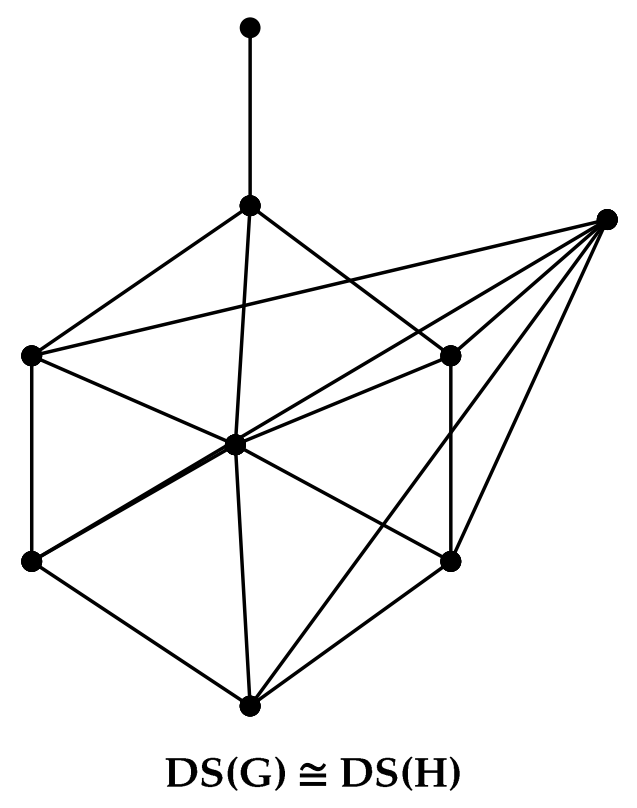

Figure 8 
Yet another condition for the existence of non isomorphic graphs with same degree splitting graph has been discussed in the following theorem.

Theorem 2.4 In a graph G with $\left|V_{k}\right| \geq 2$, for some $k \geq 2$, if there exists a distinguished vertex $v$ such that $N(v)=V_{k}-\{u\} \cup\{w\}$, where $u \in V_{k}$ and $w$ is the distinguished vertex of degree $\mathrm{k}+1$, and if $<\mathrm{G}-\{\mathrm{u}, \mathrm{v}\}>¥<\mathrm{G}-\{\mathrm{v}, \mathrm{w}\}>$, then there exists a graph $\mathrm{H}$ such that $\mathrm{G} ¥ \mathrm{H}$ and $\mathrm{DS}(\mathrm{G}) \cong \mathrm{DS}(\mathrm{H})$.

Proof Let $G$ be any graph with vertex set $V(G)=\left\{u, v, w, v_{1}, v_{2}, \ldots, v_{n-3}\right\}$ where $v$ and $w$ are distinguished vertices of degree $\left|V_{k}\right|$ and $k+1$ respectively. Let $u$ be a vertex of degree $k$. Let $N(v)=V_{k}-\{u\} \cup\{w\}$. Consider the degree splitting graph DS(G) of G. Let $\mathrm{u}_{1}, \mathrm{u}_{2}, \ldots, \mathrm{u}_{\mathrm{m}}$ be the newly added vertices in DS(G). Let $\mathrm{u}_{\mathrm{j}}$ correspond to $\mathrm{V}_{\mathrm{k}}$, for some $\mathrm{j}, 1 \leq$ $j \leq m$.

Consider the graph $H=\left\langle v_{1}, v_{2}, \ldots, v_{n-3}, w, u, u_{j}\right\rangle$. Now we prove that $H$ is the required graph such that $\mathrm{G} ¥ \mathrm{H}$ and $\mathrm{DS}(\mathrm{G}) \cong \mathrm{DS}(\mathrm{H})$.

It is clear that $\mathrm{V}(\mathrm{H})=(\mathrm{V}(\mathrm{G})-\{\mathrm{v}\}) \cup\left\{\mathrm{u}_{\mathrm{j}}\right\}$. Hence for any $\mathrm{v}_{\mathrm{i}}, 1 \leq \mathrm{i} \leq \mathrm{n}-3, \mathrm{~d}_{\mathrm{G}}\left(\mathrm{v}_{\mathrm{i}}\right)=$ $d_{H}\left(v_{i}\right)$. The vertices $v$ and $u_{j}$ contain a neighbour of degree $k+1$ and the remaining neighbours of degree $\mathrm{k}$ in $\mathrm{G}$ and $\mathrm{H}$ respectively. 


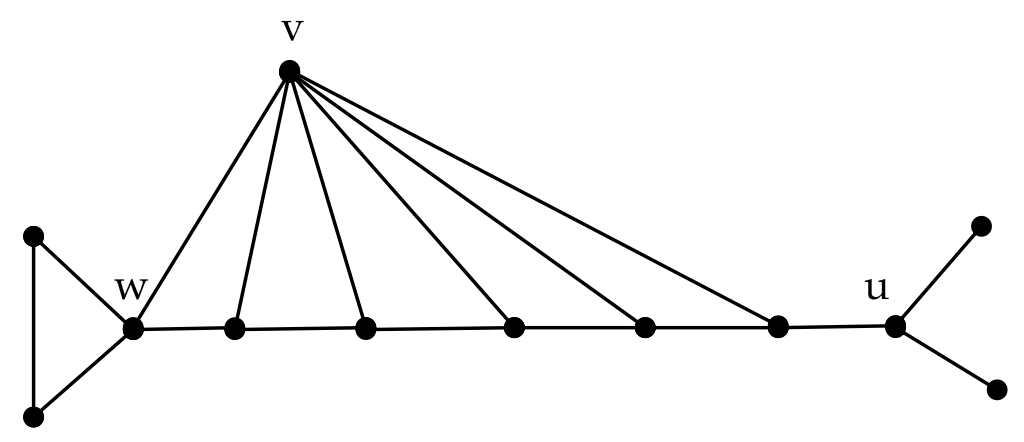

G

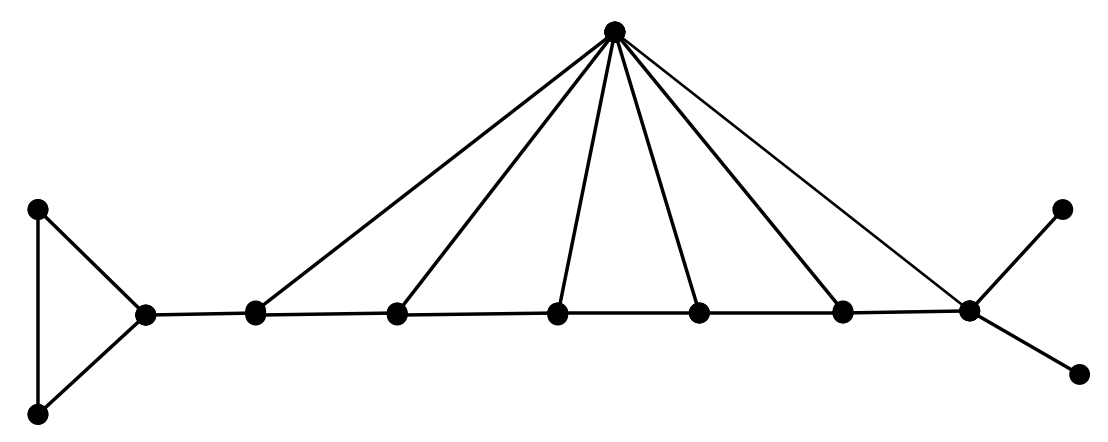

H

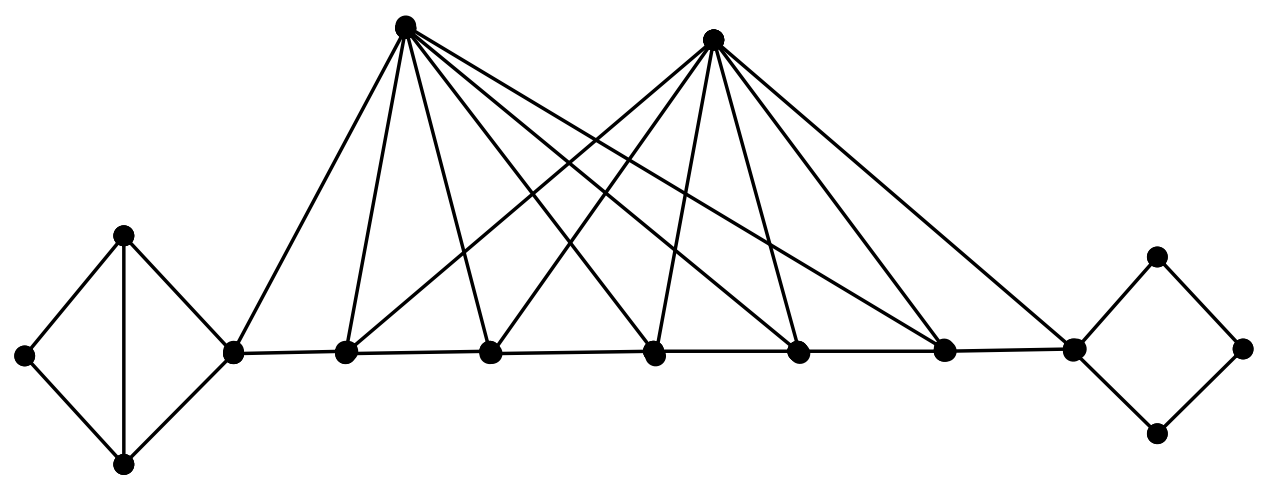

$\mathrm{DS}(\mathrm{G}) \cong \mathrm{DS}(\mathrm{H})$

Figure 9

It is easy to note that $d_{H}(w)=d_{G}(w)-1$ and $d_{H}(u)=d_{G}(u)+1$, since $u_{j} \in V(H)$. Also $d_{H}\left(u_{j}\right)=d_{G}(v)=\left|V_{k}\right|$. Hence $u_{j}$ is a distinguished vertex in $H$ since $v$ is a distinguished vertex in $\mathrm{G}$. 
But since $<G-\{\mathrm{u}, \mathrm{v}\}>¥<\mathrm{G}-\{\mathrm{v}, \mathrm{w}\}>, \mathrm{u}$ is not an isomorphic image of $\mathrm{w}$. Therefore $\mathrm{u}_{\mathrm{j}}$ which is adjacent to $\mathrm{u}$ cannot be an isomorphic image of $\mathrm{v}$ which is adjacent to $w$. Hence we can conclude that $\mathrm{G} ¥ \mathrm{H}$.

Now we construct DS(H). Both the graphs $\mathrm{G}$ and $\mathrm{H}$ have the same vertex set partition. Therefore $\left|V_{k}\right| \geq 2$ in $H$.

Also DS(H) has the same number of newly added vertices as that of in DS(G). Let them be $w_{1}, w_{2}, \ldots, w_{m}$ and without loss of generality, let $w_{i}$ correspond to the set for which $u_{i}$ corresponds to in DS(G). Then $w_{j}$ is a distinguished vertex of degree $\left|V_{k}\right|$.

Now define a mapping $f$ from the vertex set of $D S(G)$ to that of $D S(H)$ by $f(v)=$ $w_{j}, f\left(u_{t}\right)=w_{t}, 1 \leq t \leq m$ and $t \neq j, f\left(u_{j}\right)=u_{j}, f(u)=u, f(w)=w, f\left(v_{s}\right)=v_{s}, 1 \leq s \leq n-3$.

We can easily verify that $\mathrm{f}$ is an isomorphism. Hence $\mathrm{DS}(\mathrm{G}) \cong \mathrm{DS}(\mathrm{H})$.

As an example, graphs $\mathrm{G}$ and $\mathrm{H}$ with the required conditions and their degree splitting graphs are shown in Figure 9.

The following theorem gives a method of constructing two non isomorphic graphs which contains any given graph as an induced subgraph and same degree splitting graph.

Theorem 3.5 Any graph $\mathrm{H}$ is an induced subgraph of two non isomorphic graphs $\mathrm{G}_{1}$ and $\mathrm{G}_{2}$ such that $\mathrm{DS}\left(\mathrm{G}_{1}\right) \cong \mathrm{DS}\left(\mathrm{G}_{2}\right)$.

Proof Let $\mathrm{H}$ be any graph. Let us now construct two non isomorphic graphs $\mathrm{G}_{1}$ and $\mathrm{G}_{2}$ with same degree splitting graph in which $\mathrm{H}$ is an induced subgraph.

Let $\mathrm{k}=2 \mathrm{~m}, \mathrm{~m} \geq 1$ be the smallest even integer such that $\mathrm{k}>\Delta(\mathrm{H})+2$, and let $\mathrm{w}$ be a vertex of minimum degree in $\mathrm{H}$.

Consider the complete graph $K_{k}$ with vertex set $V\left(K_{k}\right)=\left\{u_{1}, u_{2}, \ldots, u_{m}, w_{1}, w_{2}, \ldots\right.$, $\left.\mathrm{w}_{\mathrm{m}}\right\}$. Let $\mathrm{F}=\left\{\mathrm{u}_{\mathrm{i}} \mathrm{w}_{\mathrm{i}} / 1 \leq \mathrm{i} \leq \mathrm{m}\right\}$ be a $1-$ factor in $\mathrm{K}_{\mathrm{k}}$. Let $\mathrm{H}_{1}=\left(\mathrm{K}_{\mathrm{k}}-\mathrm{F}\right) \vee \mathrm{K}_{1}$ and let $\mathrm{v}$ be the 
vertex of $K_{1}$. Fix an edge $e=u_{i} w_{j}, i \neq j$ in $H_{1}$. Now the graph $G_{1}$ can be obtained from $\left(H_{1}\right.$ - e) $\cup \mathrm{H}$ by adding a new vertex $x$ and two new edges $\mathrm{u}_{\mathrm{i}} \mathrm{W}$ and $\mathrm{xw}_{\mathrm{j}}$.

In a similar way, we construct the graph $\mathrm{G}_{2}$ from $\left(\mathrm{H}_{1}-\mathrm{vu}_{\mathrm{j}}\right) \cup \mathrm{H}$ by adding a new vertex $\mathrm{y}$ and two new edges vw and $\mathrm{yu}_{\mathrm{j}}$.

We claim that $\mathrm{G}_{1} ¥ \mathrm{G}_{2}$. By our construction, $\mathrm{v}$ is the only vertex of degree $\mathrm{k}$ in both $G_{1}$ and $G_{2}$. But $v$ is an $R A$ vertex in $G_{1}$ and a non $R A$ vertex in $G_{2}$. Since isomorphism preserves RA property also, it becomes obvious that $\mathrm{G}_{1} ¥ \mathrm{G}_{2}$.

Next we claim that $D S\left(G_{1}\right) \cong D S\left(G_{2}\right)$. Clearly $G_{1}$ and $G_{2}$ have same number of vertices with same vertex set partition. Also $\left|V_{i}\right|$ in $G_{1}$ is equal to that of $\left|V_{i}\right|$ in $G_{2}$. In particular, $\left|\mathrm{V}_{\mathrm{k}-1}\right|=\mathrm{k}$. Hence in constructing degree splitting graphs, both the graphs need same number of vertices. Let the newly added vertices in $D S\left(G_{1}\right)$ and $D S\left(G_{2}\right)$ are denoted by $x_{1}, x_{2}, \ldots, x_{r}$ and $y_{1}, y_{2}, \ldots, y_{r}$ respectively. Without loss of generality, let $y_{i}$ correspond to the partition of $\mathrm{DS}\left(\mathrm{G}_{2}\right)$ for which $\mathrm{x}_{\mathrm{i}}$ corresponds to in $\mathrm{DS}\left(\mathrm{G}_{1}\right)$. Now define a mapping $f: V\left(D S\left(G_{1}\right)\right) \rightarrow V\left(D S\left(G_{2}\right)\right)$ by $f(x)=y ; f(u)=u$; for any $u \in V\left(D S\left(G_{1}\right)\right)$ and $f\left(x_{i}\right)=y_{i}, 1 \leq i \leq r$. One can easily verify that $f$ is an isomorphism. Thus $D S\left(G_{1}\right) \cong$ $\mathrm{DS}\left(\mathrm{G}_{2}\right)$.

For example, two non isomorphic graphs $\mathrm{G}_{1}$ and $\mathrm{G}_{2}$ containing $\mathrm{P}_{3}$ as an induced subgraph with same degree splitting graph are shown in Figure 10. 


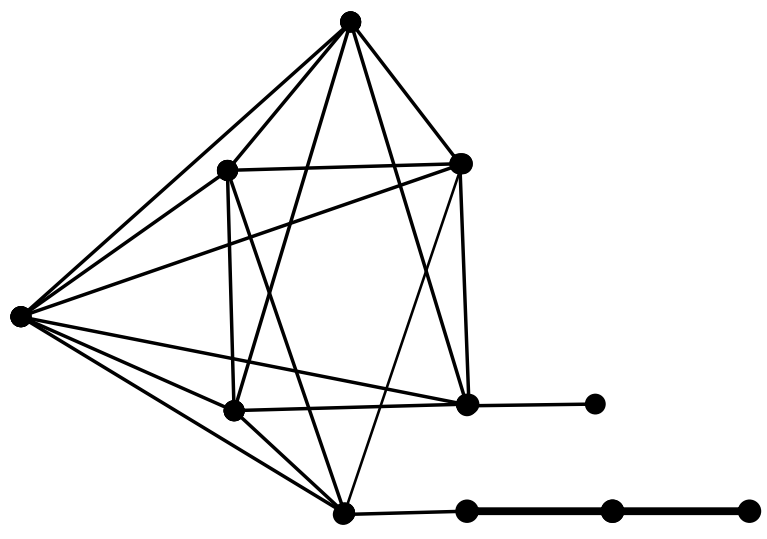

$\mathrm{G}_{1}$

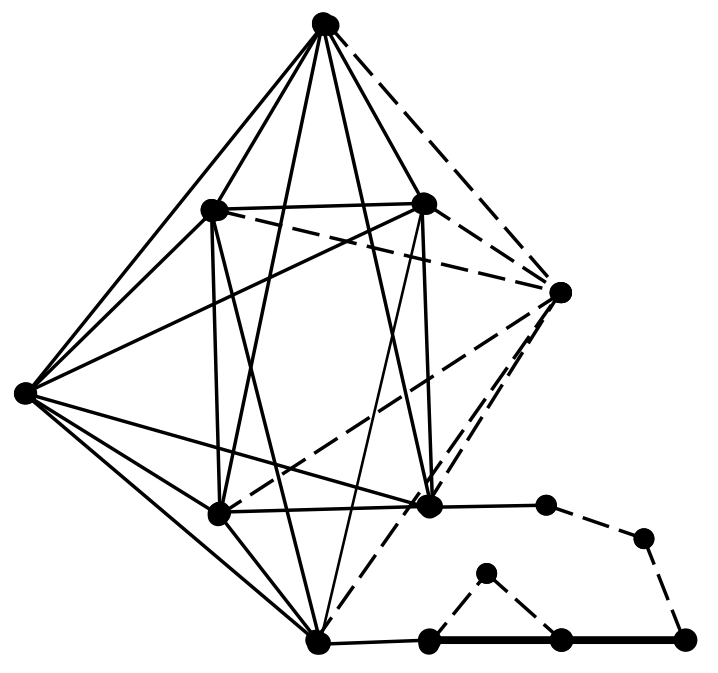

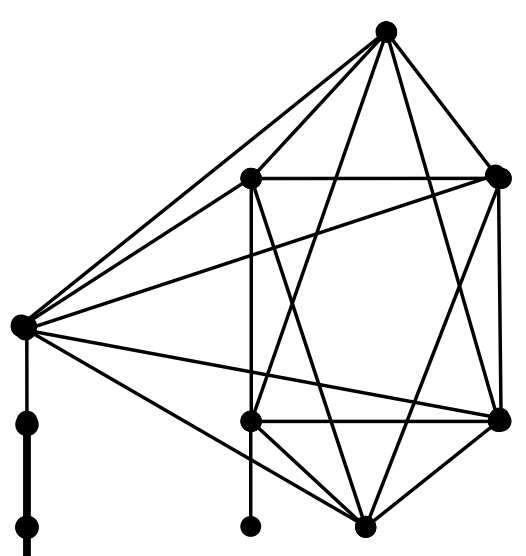

$\mathrm{G}_{2}$

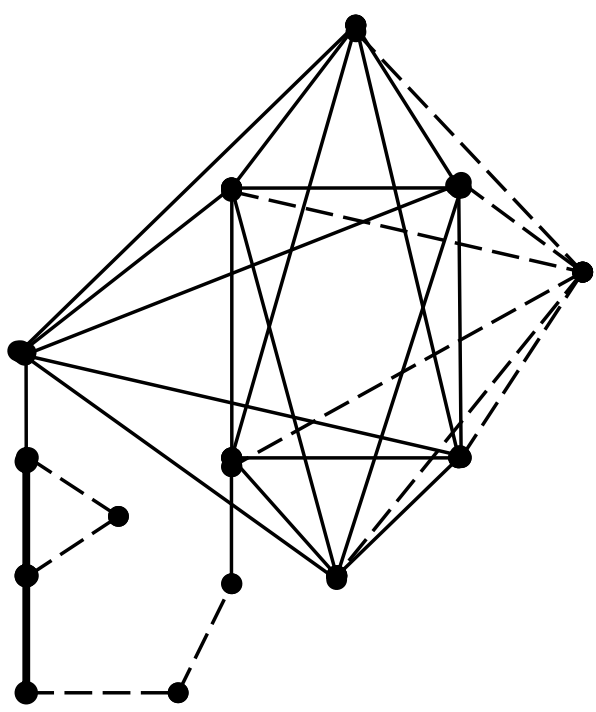

$\mathrm{DS}\left(\mathrm{G}_{1}\right) \cong \mathrm{DS}\left(\mathrm{G}_{2}\right)$

Figure 10

Theorem 2.6 Let $\mathrm{G}$ and $\mathrm{H}$ be two non isomorphic connected graphs such that $\mathrm{DS}(\mathrm{G}) \cong$ $\mathrm{DS}(\mathrm{H})$. Then $\mathrm{G}$ and $\mathrm{H}$ are of same order.

Proof Suppose, if possible, let $\mathrm{G}$ and $\mathrm{H}$ be two non isomorphic connected graphs of order $n$ and $m$ respectively with $n \neq m$ such that $D S(G) \cong D S(H)$. Therefore $D S(G)$ and $\mathrm{DS}(\mathrm{H})$ have same cardinality.

That is, $n+a=m+b$ where $a$ and $b$ are the numbers of newly added vertices in $\mathrm{G}$ and $\mathrm{H}$ respectively. Without loss of generality, assume that $\mathrm{n}<\mathrm{m}$. Consequently we 
get $a>b$. Therefore $D S(G)$ contains more newly added vertices than that in DS(H). Hence there exists a positive integer $j$ such that $\left|V_{j}\right| \geq 2$ in $G$ and $\left|V_{j}\right| \leq 1$ in $H$.

Since $\left|V_{j}\right| \geq 2$ in $G$, we have $\left|V_{j+1}\right| \geq 2$ in DS(G) and hence in DS(H). But $\left|V_{j}\right| \leq$ 1 in $\mathrm{H}$. First we assume that $\mathrm{H}$ contains a distinguished vertex $\mathrm{w}$ of degree $\mathrm{j}+1$ whose degree will be unaltered in $\mathrm{DS}(\mathrm{H})$. Then all other vertices of degree $\mathrm{j}+1 \mathrm{in} \mathrm{DS}(\mathrm{H})$ are newly added vertices.

In DS $(H)$, let $\mathrm{V}_{\mathrm{j}+1}=\left\{\mathrm{w}, \mathrm{w}_{1}, \mathrm{w}_{2}, \ldots, \mathrm{w}_{\mathrm{r}}\right\}, \mathrm{r} \geq 1$. Then clearly $\mathrm{N}\left(\mathrm{w}_{\mathrm{i}}\right) \cap \mathrm{N}\left(\mathrm{w}_{\mathrm{j}}\right)=\phi$ in $\mathrm{H}$ for all $i \neq j, 1 \leq i, j \leq r$.

Case (i) Suppose $r \geq 2$. Then in DS(H) $w_{1}$ and $w_{2}$ are two RA vertices. Therefore $D S(G)$ contains at least two RA vertices, say $v_{1}$ and $v_{2}$, of degree $j+1$.

But in $G, v_{1}$ and $v_{2}$ are of degree $j$ and hence have a common newly added vertex in $\mathrm{DS}(\mathrm{G})$, which is a contradiction. Note that the same argument holds even such distinguished vertex $w$ of degree $\mathrm{j}+1$ does not exist in $\mathrm{H}$.

Case(ii) Suppose $r=1$. Then $V_{j+1}=\left\{w, w_{1}\right\}$ in DS(H). This forces that in DS(G), $V_{j+1}=\{v$, $\left.v_{1}\right\}$. But $\left|V_{j}\right| \geq 2$ in $G$. Therefore $v$ and $v_{1}$ are of degree $j$ in $G$ and have a common neighbour of degree two in DS(G).

Therefore in $\mathrm{H}, \mathrm{w}$ must be adjacent to a pendant vertex $\mathrm{u}$ and there must be $\mathrm{j}$ more pendant vertices, say $\mathrm{u}_{1}, \mathrm{u}_{2}, \ldots, \mathrm{u}_{\mathrm{j}}$ in $\mathrm{H}$ to have $\mathrm{w}_{1}$ to be $\mathrm{a}(\mathrm{j}+1)-\mathrm{RA}$ vertex.

In $\mathrm{DS}(\mathrm{H}), \mathrm{d}^{*}\left(\mathrm{u}_{\mathrm{i}}\right)=2$. Therefore in $\mathrm{G}, \mathrm{v}$ must be adjacent only to pendant vertices so that their degrees get increased to two in DS(G).

Then the induced subgraph of $\mathrm{G}$ induced by $\mathrm{N}[\mathrm{v}]$ is the star graph $\mathrm{K}_{1, \mathrm{j}}$ and hence it forms a component in G. Clearly $\mathrm{v}_{1} \notin \mathrm{N}[\mathrm{v}]$. Therefore $\mathrm{G}$ is disconnected which is a contradiction.

This forces that $\mathrm{n}=\mathrm{m}$. The similar argument holds even such distinguished vertex $w$ of degree $\mathrm{j}+1$ does not exist in $\mathrm{H}$.

Hence the theorem.

The above result is not true if we drop the condition of connectedness of graphs. For example consider the disconnected graphs $\mathrm{G}$ and $\mathrm{H}$ of order 11 and 12 respectively and their isomorphic degree splitting graphs are shown in Figure 11. 


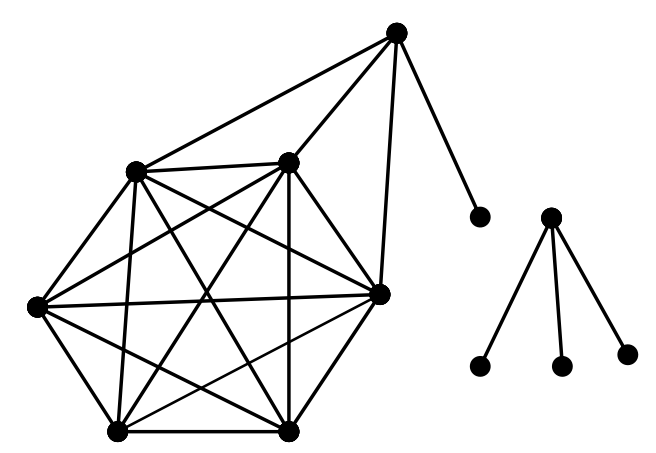

G

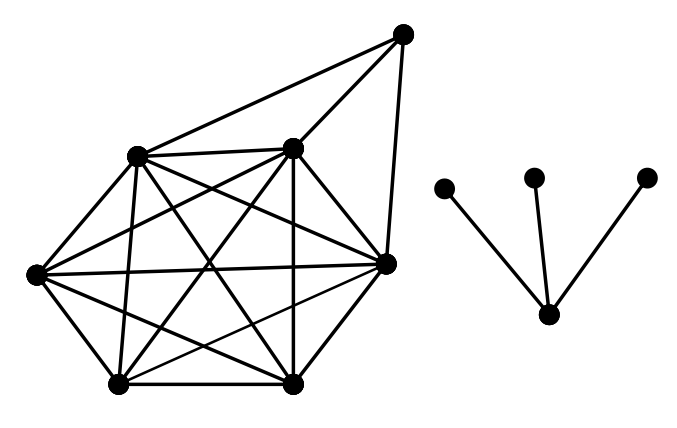

H

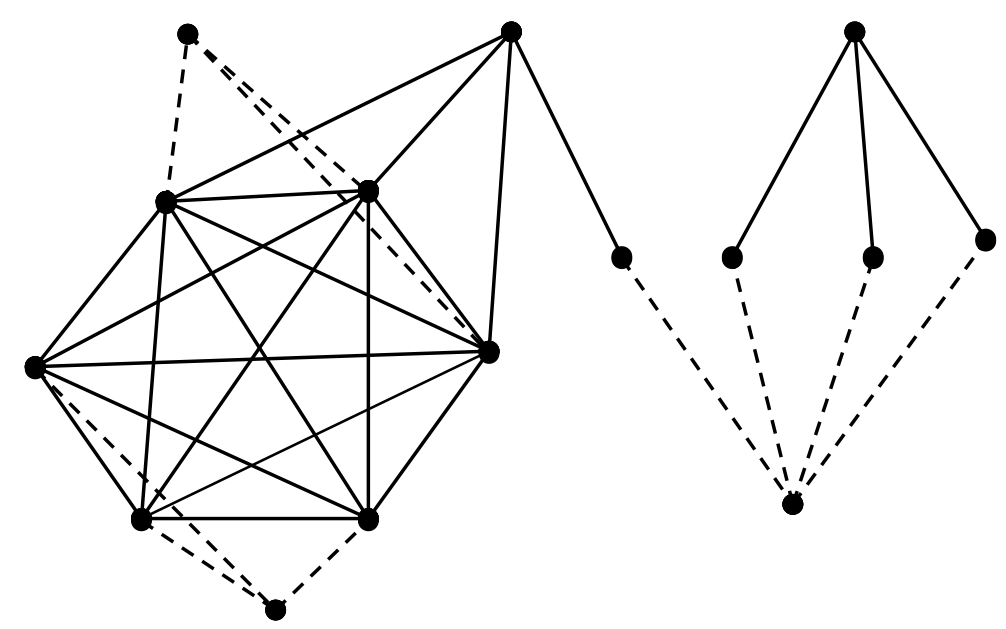

DS(G)

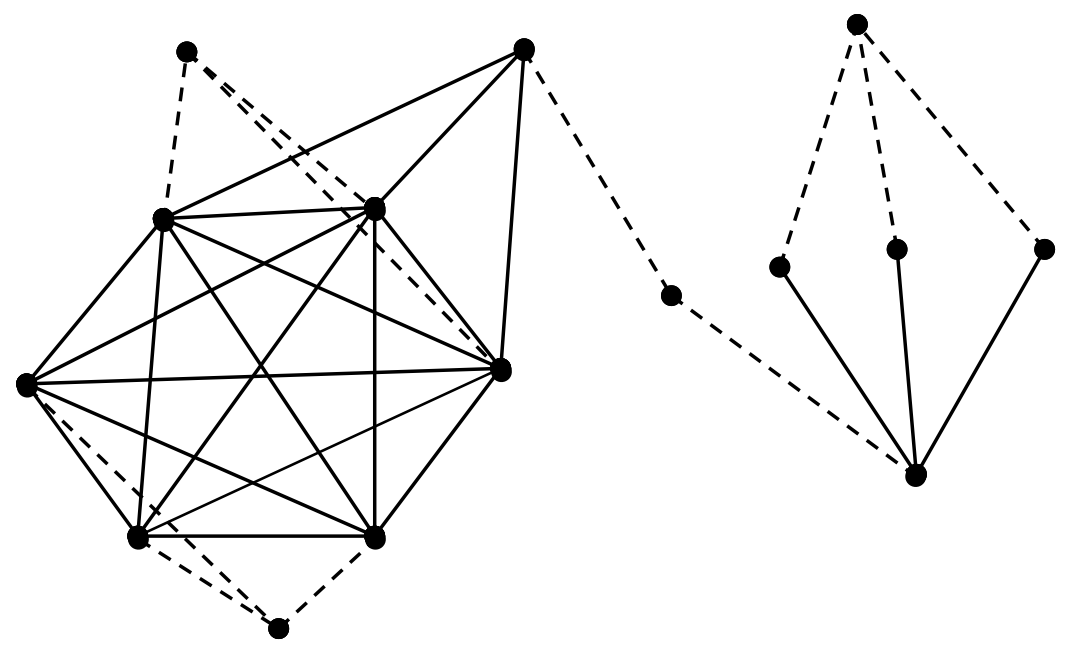

DS(H)

Figure 11 


\section{Algorithm to check a given graph to be degree splitting or not:}

We have already seen that every graph is an induced subgraph of its own degree splitting graph. On the other hand, we can think of finding the existence of induced subgraph $H$ of a graph $\mathrm{G}$ such that $\mathrm{DS}(\mathrm{H}) \cong \mathrm{G}$. That is, we are interested in finding out whether every graph is a degree splitting graph of some other graph or not. The answer is obviously 'impossible' as we have already characterized regular and biregular RA degree splitting graphs in [5]. Therefore we try to develop an algorithm to check whether the given graph is a degree splitting graph or not.

Before developing a core algorithm, we first short out the list of graphs to be actually checked. Some graphs are obviously degree splitting and some obviously not. The following facts are necessary to identify such graphs.

Fact 3.1 For the null graph $G$ of order $n, D S(G) \cong K_{1, n}$.

It is easy to note that $K_{1, n}$ is the only degree splitting graph which is acyclic. Therefore, any tree other than star is not a degree splitting graph.

Fact 3.2 A connected graph, other than star, having more than one pendant vertex is not a degree splitting graph.

For, if $\mathrm{v}$ is a pendant vertex in $\mathrm{DS}(\mathrm{G})$, then either $\mathrm{v}$ is an isolated vertex of $\mathrm{G}$ or $\mathrm{v}$ is the only pendant vertex in $G$. If $v$ is an isolated vertex of $G$, then $D S(G)$ is disconnected, a contradiction. If $\mathrm{v}$ is the only pendant vertex in $\mathrm{G}$, then $\mathrm{DS}(\mathrm{G})$ contains only one pendant vertex, a contradiction.

Fact $3.3 \mathrm{C}_{4}$ is the only unicyclic degree splitting graph.

For, every newly added vertex forms a new cycle in DS(G). Therefore G must be a tree which allows only one new vertex in $D S(G)$. This is possible only when $G \cong P_{3}$ for which $\mathrm{DS}(\mathrm{G}) \cong \mathrm{C}_{4}$. 
Fact 3.4 A degree splitting graph $\mathrm{DS}(\mathrm{G})$ is disconnected if and only if $\mathrm{G}$ is disconnected with components $\mathrm{G}_{1}, \mathrm{G}_{2}, \ldots, \mathrm{G}_{\mathrm{m}}$ and there exists a subgraph $\mathrm{H}=G_{i_{1}} \cup G_{i_{2}} \cup \ldots \cup G_{i_{k}}$ where $1 \leq \mathrm{i}_{\mathrm{j}} \leq \mathrm{m}, 1 \leq \mathrm{j} \leq \mathrm{k}$ such that $\mathrm{D}(\mathrm{H}) \cap \mathrm{D}(\mathrm{G}-\mathrm{H})=\phi$.

For, a degree splitting graph $\mathrm{DS}(\mathrm{G})$ is disconnected, implies that, $\mathrm{G}$ is disconnected and suppose $G$ does not contain any such subgraph $H$, such that $\mathrm{D}(\mathrm{H}) \cap$ $\mathrm{D}(\mathrm{G}-\mathrm{H})=\phi$. Then for every induced subgraph $\mathrm{H}_{1}$ of $\mathrm{G} \mathrm{D}\left(\mathrm{H}_{1}\right) \cap \mathrm{D}\left(\mathrm{G}-\mathrm{H}_{1}\right) \neq \phi$ and hence $\mathrm{DS}(\mathrm{G})$ is connected, which is a contradiction. The converse is obvious.

Fact 3.5 A disconnected graph is a degree splitting graph, if and only if, each of its components is a degree splitting graph.

Hence we can restrict ourselves to a procedure that checks a connected graph to be degree splitting or not. By Theorem A, the degree splitting graph $\mathrm{DS}(\mathrm{G})$ is regular if and only if $G \cong K_{r}$ or $\left(K_{2 k}-F\right) \vee K_{1}$, where $F$ is a 1-factor of $K_{2 k}$ and $k \geq 1$ and by Theorem B, for a graph $\mathrm{G}, \mathrm{DS}(\mathrm{G})$ is a biregular RA graph, if and only if, $\mathrm{G} \cong \mathrm{K}_{1, \mathrm{n}}$ or $K_{n, 2 n+1}^{*}$.

Hereafter in this section by a graph G, we mean a connected, cyclic, but not unicyclic, non - regular and non - RA graph. In order to check whether the given graph is degree splitting or not, we have to search for the existence of an induced subgraph $\mathrm{H}$ in $\mathrm{G}$, such that $\mathrm{DS}(\mathrm{H}) \cong \mathrm{G}$.

First of all, let us partition the vertex set $V(G)=S \cup V_{1} \cup \ldots \cup V_{k}$ where $S=\{w \in$ $\mathrm{V}(\mathrm{G}) / \mathrm{w}$ is a $\mathrm{RA}$ - vertex $\}, \mathrm{V}_{\mathrm{i}}=\{\mathrm{v} \in \mathrm{V}(\mathrm{G}) / \mathrm{d}(\mathrm{v})=\mathrm{i}$ and $\mathrm{v} \notin \mathrm{S}\}$. When $\mathrm{S}=\phi$, then $\mathrm{G}$ contains no RA vertices and hence fails to be a degree splitting graph and the procedure stops here itself. Therefore assume that $S \neq \phi$. Also since $G$ is a non RA graph, $V(G) \neq S$ and so at least one such set $V_{i}$ exists.

Note 3.6 If $G$ is a degree splitting graph of $H$, then $\left|V_{j}\right| \geq 2$ in $G$ implies that $\left|V_{j-1}\right| \geq 2$ in $\mathrm{H}$. 
Before constructing an algorithm to check whether a given graph is a degree splitting graph or not, first we prove few theorems which give necessary conditions for a graph to be degree splitting.

Theorem 3.7 Let $\mathrm{G}$ be the graph with vertex set partition defined as above. Suppose for any set $\mathrm{V}_{j}$ with $\left|\mathrm{V}_{\mathrm{j}}\right| \geq 2$, there is no vertex $\mathrm{w} \in \mathrm{S}$, such that $\mathrm{V}_{\mathrm{j}} \subseteq \mathrm{N}(\mathrm{w})$ or $\mathrm{V}_{\mathrm{j}}-\{\mathrm{v}\} \subseteq$ $\mathrm{N}(\mathrm{w})$ for some $\mathrm{v} \in \mathrm{V}_{\mathrm{j}}$, then $\mathrm{G}$ is not a degree splitting graph.

Proof Let $G$ be any graph with no such RA vertex w. That is $G$ contains a vertex set partition $V_{j}$ with $\left|V_{j}\right| \geq 2$ and no RA vertex w. On contrary, if possible, suppose $G$ is a degree splitting graph of some graph $\mathrm{H}$. Then $\mathrm{DS}(\mathrm{H})=\mathrm{G}$. Now by Note $3.6,\left|\mathrm{~V}_{\mathrm{j}-1}\right| \geq 2$ in $\mathrm{H}$.

It is easy to note that if $v \in V_{j}$ in $G$, then $v$ must be of degree $j-1$ in $H$ or $v$ is a distinguished vertex of degree $\mathrm{j}$ in $\mathrm{H}$. Since $\left|\mathrm{V}_{\mathrm{j}-1}\right| \geq 2$ in $\mathrm{H}$, then by definition a new vertex $\mathrm{w}_{1}$ is added corresponding to $\mathrm{V}_{\mathrm{j}-1}$ in $\mathrm{DS}(\mathrm{H})=\mathrm{G}$.

Suppose $H$ does not contain a distinguished vertex $v \in V_{j}$. Then $N\left(w_{1}\right)=V_{j}$ in $G$ which is a contradiction. Suppose $H$ contains a distinguished vertex $v \in V_{j}$. Then $N\left(w_{1}\right)=V_{j}-\{v\}$ in $G$, again a contradiction. Hence $G$ cannot be degree splitting.

Theorem 3.8 In a graph $G$, if for some $j,\left|V_{j}\right|=1$ and $V_{j} \cap N(S)=\phi$ and if $\left|V_{j+1}\right|>1$, then $G$ is not degree splitting.

In other words, if $G$ contains a distinguished non RA vertex of degree $j$ whose neighbours are all non RA vertices and if $\left|V_{j+1}\right|>1$, then $G$ is not degree splitting. Proof Let $G$ be a degree splitting graph of some graph $H$. Let $\left|V_{j}\right|=1$ for some $j$ in $G$. In addition, suppose that $V_{j} \cap N(S)=\phi$ in $G$. The distinguished vertex $v$ of degree $j$ in $G$ is a non RA vertex and $\mathrm{N}(\mathrm{v})$ contains no RA vertices. Therefore $\mathrm{v}$ is a distinguished vertex in $H$ also. Also if $\left|V_{j+1}\right| \geq 2$ in $G$, then by Note 3.6, $\left|V_{j}\right| \geq 2$ in $H$, which is a contradiction. Hence $\mathrm{G}$ cannot be degree splitting. 
Corollary 3.9 A degree splitting graph with $\left|V_{j}\right| \geq 2$ cannot contain a distinguished vertex of degree $j-1$.

Theorem 3.10 A degree splitting graph G cannot contain a degree j such that all vertices of degree $\mathrm{j}$ are all RA vertices.

Proof Suppose a degree splitting graph contains a degree $j$ such that all of its vertices are RA vertices. Then the induced subgraph of vertices of degree $j$ is an RA graph and thus by Theorem $\mathrm{C}$, it is isomorphic to a regular graph or a biregular bipartite graph, which forms a component of $G$. This is impossible since $G$ is connected. Therefore $G$ cannot contain a degree $j$ such that all vertices of degree $j$ are all RA vertices.

Theorem 3.11 An RA vertex $\mathrm{v}$ in a graph $\mathrm{H}$ is a $\mathrm{k}$ - RA vertex in the degree splitting graph $\mathrm{G}$ of $\mathrm{H}$, if any one of the following is true:

(i) $\quad \mathrm{v}$ is a distinguished RA vertex in $\mathrm{H}$.

(ii) $\quad\left|\mathrm{V}_{\mathrm{d}(\mathrm{v})}\right|=\mathrm{k}+1$ in $\mathrm{H}$.

Proof Let $\mathrm{H}$ be any graph in which $\mathrm{v}$ is a $\mathrm{k}-\mathrm{RA}$ vertex. Then $\mathrm{d}^{*}(\mathrm{v})=\mathrm{d}(\mathrm{v})$ or $\mathrm{d}(\mathrm{v})+1$ in G. Clearly $\mathrm{v}$ is a non - pendant vertex in $\mathrm{H}$. Hence $\mathrm{N}(\mathrm{v})\left(\subseteq \mathrm{V}_{\mathrm{k}}\right)$ contains at least two vertices. Suppose that $v$ is an RA vertex in $G$ also. If $d^{*}(v)=d(v)$, then clearly $v$ is a distinguished RA vertex in $\mathrm{H}$ in which case it is a $(k+1)-R A$ vertex in $G$.

On the other hand, let $d^{*}(v)=d(v)+1$ in G. Then there must be a newly added vertex $w$ such that $w \in N(v)$ in $G$. By the definition of degree splitting graph, every neighbour of $\mathrm{v}$ is of degree $\mathrm{k}+1$ in $\mathrm{G}$. Therefore, $\mathrm{d}(\mathrm{w})=\mathrm{k}+1$. Obviously, $\mathrm{d}(\mathrm{w})$ is nothing but $\left|V_{d(v)}\right|$ in H. Hence the theorem. 
Using the theorems let us now develop an algorithm which checks the given graph to be degree splitting or not. Let $\mathrm{G}$ be the given graph with vertex set partition as mentioned earlier.

\section{Algorithm 3.12}

Step 1 Set $\mathrm{m}=1$ and $\mathrm{H}=\mathrm{G}$.

Step 2 Check whether $m \leq \Delta(\mathrm{H})$, if yes, continue. Otherwise goto Step 10 .

Step 3 Check whether $\left|V_{m}\right|=0$. If yes, $m=m+1$, goto Step 2 .

Step 4 Check whether $\left|V_{m}\right|>1$, if yes, continue. Otherwise goto Step 8 .

Step 5 Check for the existence of $\mathrm{w}_{\mathrm{m}} \in \mathrm{S}$, such that $\mathrm{N}\left(\mathrm{w}_{\mathrm{m}}\right) \supseteq \mathrm{V}_{\mathrm{m}}$. If exists, let $\mathrm{H}=\mathrm{H}-\mathrm{w}_{\mathrm{m}}$ and $\mathrm{m}=\mathrm{m}+1$, goto Step 2 .

Step 6 Check for the existence of $\mathrm{w}_{\mathrm{m}} \in \mathrm{S}$, such that $\mathrm{N}\left(\mathrm{w}_{\mathrm{m}}\right) \supseteq \mathrm{V}_{\mathrm{m}}-\{\mathrm{v}\}$ for some $\mathrm{v} \in \mathrm{V}_{\mathrm{m}}$. If exists, continue. Otherwise goto Step 11.

Step 7 Check whether $\left|V_{m+1}\right| \leq 1$. If yes, $H=H-w_{m}$, and $m=m+1$, goto Step 2 . Otherwise goto Step 11.

Step 8 Check whether $V_{m} \cap N(S) \neq \phi$. If yes, then $H=H-w_{m}$, where $w_{m} \in S$ such that $\mathrm{N}\left(\mathrm{w}_{\mathrm{m}}\right) \supseteq \mathrm{V}_{\mathrm{m}}$, and $\mathrm{m}=\mathrm{m}+1$, goto Step 2 .

Step 9 Check whether $\left|V_{m+1}\right| \leq 1$. If yes, and $m=m+1$, goto Step 2. Otherwise goto Step 11 .

Step 10 Check whether $\mathrm{d}_{\mathrm{G}}(\mathrm{v})=\mathrm{d}_{\mathrm{H}}(\mathrm{v})+1$, for all non distinguished vertex $\mathrm{v} \in \mathrm{S}$ in $\mathrm{H}$. If yes, $\mathrm{G}$ is degree splitting, goto End.

Step $11 \mathrm{G}$ is not degree splitting.

End 


\section{REFERENCES}

[1] R. Aravamuthan and B. Rajendran, Graph equations involving antipodal graphs, Presented at the seminar on Combinatorics and applications held at ISI (Culcutta during 14-17 December 1982), 40-43.

[2] R. Aravamuthan and B. Rajendran, On antipodal graphs, Discrete Math. 49 (1984), 193-195.

[3] S. Avadayappan and M. Bhuvaneshwari, A note on radial graphs, J. Mod. Sci. 7 (2015), 14- 21.

[4] S. Avadayappan and M. Bhuvaneshwari, Cosplitting graph and coregular graph, Int. J. Math. Soft Comput. 5 (2015), $57-64$.

[5] S. Avadayappan and M. Bhuvaneshwari, Some results on Degree splitting graph, Int. J. Adv. Innovat. Res. 5 (3) 2016.

[6] S. Avadayappan, M. Bhuvaneshwari, R. Iyswarya, $\gamma$ - splitting graph, Int. J. Rese. Appl. Sci. Eng. Technol. 4 (2016), 670 - 680.

[7] S. Avadayappan, M. Bhuvaneshwari, Rajeev Gandhi, Distance in degree splitting graphs, Int. J. Eng. Res. Appl. 7 (2017), $14-71$.

[8] S. Avadayappan, M. Bhuvaneshwari, B. Vijayalakshmi, $\beta$ - splitting graph, Int. J. Sci. Rev. Res. Eng. Technol 1 (2016), $84-101$.

[9] S. Avadayappan, M. Muthuchelvam, Neighbourly regular strength of a graph Ars Combinatoria (Accepted).

[10] R. Balakrishnan and K. Ranganathan, A Text Book of graph Theory, Springer-Verlag, New York, Inc, (1999).

[11] KM. Kathiresan and G. Marimuthu, Further results on radial graphs, Discussions Mathematicae, Graph Theory, 30 (2010), 75-83.

[12] KM. Kathiresan and G. Marimuthu, A study on radial graphs, Ars Combin. (to appear).

[13] R. Ponraj and S. Somasundaram, On the degree splitting graph of a graph, Natl. Acad. Sci. Lett. 27 (2004), $275-278$.

[14] Sampath Kumar.E, Walikar.H.B, On the Splitting graph of a graph, J. Karnatak Uni. Sci. 25(1980), 13. 